\title{
Resistance or Reiteration? Rethinking Gender in DJ Cultures
}

\author{
Tami Gadir
}

Abstract

Many practices of contemporary DJ-driven electronic dance music derive from 1970 s club scenes in the United States, which were welcoming spaces for people who otherwise encountered prejudice for their gender identities and sexual orientations. Through their prominence in dance music literature, these scenes, along with British rave culture, have come to represent a broader conception of a global 'alternative dance music culture' that incorporates various communitarian ideologies-including non-discriminatory and nonpatriarchal gender relations. In this paper I offer a critique of such celebratory interpretations. First, I suggest that these scenes, often framed as formative of dance music cultures worldwide, are exceptional rather than typical, and that their politics have been projected onto other scenes. Second, I highlight how troubling gender discrimination is present even in 'alternative' settings where participants are more conscious of political and social issues, including gender. I illustrate these points through interviews in a number of countries with women DJs who describe numerous instances of gender-related prejudice, and through interviews with men, who articulate some of these prejudices. The interviews reveal a series of dimensions of the gendering of DJ-oriented dance cultures, and how they are suffused with problematic attitudes towards gender. My research therefore challenges the celebratory interpretations of many DJ music scenes.

Keywords: DJ; Gender; Sound; Femininity; Dancing; Technology

While feminist movements continue to ebb and flow, instances of gender prejudice, discrimination and harassment nevertheless feature prominently in many aspects of contemporary culture. Musical communities are no exception. For example, musical practices associated with power and leadership, such as conducting, have long been stereotyped as masculine domains (Cheng, 1998, pp. 81-82; Robertson, 1987). At the same time, certain scholars have shown that music is a resource that can be used to build inclusive and politically progressive senses of self and community (cf. Hesmondhalgh, 2008; Waters, 2016). This optimistic perspective on music features prominently in studies of DJs and electronic dance music cultures, albeit with some exceptions (e.g. Saldanha, 2001; Thornton, 1995). Indeed, accounts of the promise of electronic dance music tend to pinpoint specific cases of consciously political scenes, such as US disco, house and techno (Fikentscher, 2000; Lawrence, 2003; Shapiro, 2000; Sicko, 1999) as well as British rave (Brewster \& Broughton, 1999; McRobbie, 1994; Pini, 2001; Reynolds, 2008). To take a particular instance: gay disco clubs in New York, which thrived against the backdrop of heteronormativity that prevailed across the United States during the 1970s, have been described as safe 
spaces for sexually marginalised individuals (Brewster \& Broughton, 1999, pp. 136137; Fikentscher, 2000; Reynolds, 2008, pp. 14-24, 28-32). ${ }^{1}$ In addition, McRobbie (1994) and Pini (2001) have highlighted the rave dance floor as a space that can free women from repressive gender dynamics. ${ }^{2}$ Pini focuses on accounts by women participants that emphasise the "adventure" narrative' of rave dancing:

What raving appears to offer these women are the conditions of possibility for experiences of adventure, exploration and discovery: experiences which are often denied them within other spheres of their lives...The 'elsewheres' or 'other worlds' opened up through raving are, I want to argue, particularly significant sites for expressing and exploring what can be thought of as a collapse of femininity's traditional landmarks. (Pini, 2001, pp. 13-14)

Pini goes on to link rave's potential to be a feminist space to Braidiotti and Haraway's theories or 'political fictions' of the 'Nomadic Subject' and Cyborg, respectively (2001, pp. 155-157). Pini's overall account might be described as 'post-feminist', in that it ascribes a sexual politics to dance music cultures that asserts their relative freedom from gender discrimination.

In one sense, works of this optimistic tone are symptomatic of how notions of subcultural resistance continue to shape the way scholars conceive of dance music communities. ${ }^{3}$ Such scholars tend to offer interpretations oriented towards special, 'alternative' scenes that promote the experiential, spiritual or political significance of participation (Lawrence, 2003; O'Grady, 2015; Petiau, 2015; Pini, 2001; Rietveld, 2011; Schmidt, 2015; St. John, 2013; Van Veen, 2010; Vitos, 2014; Watson, 2004). Accounts by scholars such as Sophie Watson, for example, frame dance music cultures as instances of 'emergent democratic possibilities', without substantiating what these notions might mean in practice (2004, pp. 216-217). Making a similar argument, Van Veen (2010) sees rave culture as having 'dissolved the boundaries of labour from leisure' (p. 30). Van Veen attaches this idea more concretely to the antiinstitutional, often illegal practices of rave: 'from its embodied and technological practices to its production of eestatic and collective subjectivities-[rave] complicated the very question of the political, the communal and the ethical' (p. 31). For Van Veen, raving constitutes a communal act of legal and cultural 'disobedience-through harnessing the expansion and fluidity of work and leisure characteristic of late capitalism' (pp. 35-36). In addition, the celebratory politicisation of particular dance music cultures is promoted by Rietveld (2011) through a perceived relationship between musical sound and culture. Specifically, Rietveld argues for an alternative politics in which house music's sonic features (repetition and syncopation) are reflected in its political history, with effects on dancers.

My central criticism of such scene-specific scholarship is that it is anachronistic, in a sense, and gender provides one corrective to such utopian readings. That is to say, the dance music settings highlighted in Pini's writing and in other historical accounts (e.g. Lawrence, 2003) may indeed have been politically progressive, and more conducive than other scenes to unprejudiced interactions between genders. Yet, these standout circumstances were not so widespread that they 
should continue to underpin contemporary scholarly theorisations of gender in dance music. Furthermore, while the politics of such historical settings as New York disco or early British rave scenes continue to be enacted to varying degrees in particular dance music communities across the world, no space or setting, however 'alternative', is wholly immune to gender problems.

Farrugia (2012) and Gavanas and Reitsamer (2013) begin to open up a counter-narrative by redressing women practitioners' lack of visibility in the dance music literature. 4 These texts are the only in-depth examinations of matters pertaining specifically to women DJs in three decades of scholarly writing about dance music. I build on this work, suggesting that prejudice against women-as performers, clubbers and dancers-is commonplace in many contemporary dance music scenes. These scenes include 'mainstream' clubbing communities defined by commercial Top-40 music, alcohol consumption, picking-up and hedonism, as well as 'alternative' events focused on niche musical genres (e.g. Malbon, 1999) in which participants identify with leftist, communitarian ideologies, and which promoters market on the basis of social and environmental consciousness (e.g. St. John, 2001). I draw on examples selected from a global spread of 70 interviews -26 men and 44 women-conducted with clubbers, DJs and producers between the years 2010 and 2015. Thirty-three of these women are DJs. The excerpts in this article, from interviews with DJs (both men and women) from Australia, Iceland, Norway, Taiwan, the United Kingdom and the United States, demonstrate the extent and variety of gender issues that permeate almost every account. ${ }^{5}$ In particular, these interviews suggest that the theme of gender liberation propagated by much scholarly writing on dance music contrasts starkly with the sexist articulations and behaviours of participants on and off the dance floor, and behind the DJ booth.

In order to make these points, I begin by addressing the hyperfeminine stylisation of women DJs during and between performances. Subsequently, I explore an assumption, prominent among the participants in my research, that sounds can be considered gendered, such that 'fluffy' sounds equate to 'girly' music, and that femininity as expressed through dance movements is incongruous with 'sophisticated' or 'good' music, which participants presume to be masculine. It is not my intent to crudely suggest that the disparity between my research and the literature invalidates any optimistic readings of dance music practices. Certainly, an alternative politics might be meaningfully embodied and 'imagined' in some dancing spaces more than in others, as O'Grady (2015) argues. I provide some tangible examples of these possibilities in the latter part of this article. Nevertheless, in most settings, where such ideals are not shared or practised widely, the lived experience of gender discrimination prevents such imaginings or enactments from being fulfilled. Thus, my research findings prompt me to underline the plethora of dance spaces-both those considered 'alternative' and those considered 'mainstream'-in which gender asymmetries both persist, and are reproduced or even entrenched.

\section{'She Can DJ'}


The vaguely expressed political potentialities of dance music settings are contradicted by the everyday lived, material realities experienced by women who participate in dance music cultures. In a clear strategy of segmentation of the market for DJs, for example, event promoters and record label marketing executives tend to portray women DJs as categorically, commercially and socially separate from what has been the reigning, almost-exclusive image of the male DJ (cf. Gavanas \& Reitsamer, 2013). To achieve this segmentation, the industry reinforces particular enactments and signifiers of woman-DJing, involving gendered symbols and behaviours that are portrayed as radically distinct from those associated with men. A prominent example of this segmentation is the way companies and networks such as femaledjs. com and female-djs.com focus on the promotion and management of women DJs, marketing them by use of such persisting symbols of femininity as pink and purple colour schemes and web space dominated by 'sexy' photographs. ${ }^{6}$ Competitions such as 'She Can DJ' have promoted not only the musical performances of the women candidates but also their aptitude for and skills in displaying an idealised hyperfemininity through fashion presentations. Key sponsors of the 'She Can DJ' competition have included not only EMI Music, but corporations such as Rimmel cosmetics and 'designer bargain' clothing chain DFO (Direct Factory Outlet). ${ }^{7}$ Such blatantly gendered branding epitomises gender stereotyping across contemporary dance music settings, while also reflecting what it means to perform gender in the everyday sense (Butler, 1988, pp. 519-520, 522).

Among the themes discussed in depth during my interviews is the conscious stylisation of femininity and the performance of gender both on and off stage. ${ }^{8}$ Hannah, for instance, a commercially successful Australian DJ, takes the view that for creative practitioners like herself, there is little choice but consciously to draw attention to what are likely to be perceived as their sexually desirable feminine bodies:

Yeah, a lot of girl DJs are sexy, and they do put out sexy images...Guys say that on my Instagram, I've noticed that: 'You only get shows 'cause you're hot'...We have a common understanding that it's important to look hot to work as what we do... Like, we all understand that you have to be marketable, and people will have to want to be engaged with what you're doing...you get that that's part of the job...I suppose, if you've got a good-looking woman in a position of power doing something that they kind of wish they could do.... I definitely think it's problematic, because...for example, if I was short and really overweight, with bad acne, but I was a killer DJ, no one would come listen to me! And that sucks.

Melbourne-based DJ Christine also believes that the criteria on which many women are judged is sexual desirability:

Being a transwoman, I've been on both sides of the nightclub. I've had the discussions, presenting as male. And I've been privy to the discussions about 
why someone would like a particular DJ. And they're not great, they're pretty awful discussions. They're like, 'they're a babe, they're hot. Oh and they really know about their music too'. It's so misog[ynistic]...

In order to survive in the dance music milieu, then, women must continuously negotiate these issues to do with their appearance and desirability.

Gender discrimination impacts not only on the performance event but beforehand, during processes of booking for gigs. This is illustrated by Edda, a DJ from Oslo:

I remember this one [e]mail that I got from Portugal. They wanted to book me. And then they were asking, 'are you a model?' And I was like, 'no, why? 'No, 'cause, then you won't get the job, because you're not a model, because that's what we want'. So I'm like, 'ok, so what about the music quality? What about the technical quality?' And it didn't matter. So I was like, 'fuck off! I don't want this. This is not me!'...[Another time] this one place I played...I went there to play, and I got so much good feedback, and I was like, ok, good, maybe I'll come back here...And then...[the booking agent] told me...'you're not worth the money...you should have been a lot more undressed for that price'.

Gender-related discrimination can manifest in yet more disturbing forms of harassment, such as in Hannah's account of a recent performance:

I actually finished 15 minutes early, [and] walked off stage, because everyone was screaming, 'tits out for the boys, tits out for the boys!'. Even the girls...9 And, so...I pulled the sound down, got on the mic, and I was like: 'I find it really rude that you're saying that when I'm performing for you guys. If you want to see tits, go home and ask your girlfriend to [show you] her tits'...And they kept doing it...There [were] five hundred people in the venue, and probably half of them were screaming this chant, over and over...And then the third song, I mixed it in, and I was almost in tears. I was like, this is so shit. So I just said to the [next] DJ, 'can you jump on? I'm leaving' ${ }^{10}$

In another example, María, a wedding and events DJ in Reykjavík, explained her decision to turn down Friday and Saturday night performances 'because I simply cannot deal with the harassment of people not in the same state of mind as I am'. In our dialogue, María linked this harassment to her gender identity: 'it has to do with the fact that I'm a girl. People come to the booth and they pretend that I don't know what I'm doing'. ${ }^{11}$ The assumption that women are less competent than men is reinforced by the account of a New York DJ, Mel, whose interest in DJing was met with resistance by her male peers:

Some friends had started to get into DJing that I knew...and they were kind of playing around, and I was like, 'Oh, well, you know, I've always been into DJs and what have you... and you know, maybe you could show me'; and they were like, 'No: you're not gonna learn because you're a girl'. 
This prejudice extends beyond practical and technical competency to aesthetic worth -that is, the idea that men's music, whatever its form, is authentic and deep, while women's music is manufactured and superficial (cf. Frith \& McRobbie 1990). Thus, when a woman performs music that is judged by a male participant to be 'good', this is automatically assumed to result from the influence of her male mentors. A Chinese psytrance DJ based in Taipei, Fenfang, described, via email, a common encounter at gigs:

It's totally annoying that after I play, people would say: that was awesome! What's the song played around 4omin? Is that from your boyfriend?...And no one asked him if I gave him music. ${ }^{12}$

These experiences go some way towards explaining the ubiquity of the compound terminology used by participants-'girl DJ' or 'female DJ'-in contrast to the dominant masculine category of the 'DJ' who, as the naturalised term, is defined without reference to gender, exclusively by occupation.

This DJ-as-masculine by default has been addressed by Gavanas and Reitsamer, through the issue of women's exclusion from 'male-coded spaces' (2013, p. 57). This manifests in a first way through perceptions of the music technologies themselves-specifically, DJ hardware and software-as masculine (2013, pp. 53-59; cf. Armstrong, 2011, pp. 29-30; Doubleday, 2008, pp. 15-18). Incidents exemplifying this kind of perception were conveyed by almost all of my 33 women DJ interviewees. In such cases, my interlocutors describe how sound engineers, promoters, booking agents, clubbers or other DJs explicitly or implicitly suggested that the competent operation of DJ hardware and software by women DJs in performance is unlikely or unusual. These experiences are so routine that they are taken for granted, to the extent that some interviewees do not even mention them without being prompted. In one interview, a pair of DJs from Oslo (Lill and Sabine) insisted that being women in the dance music industry constituted a substantial advantage rather than a problem. They went so far as to express bewilderment at women DJs' complaints about being singled out as women. However, when asked whether their abilities to use DJ technologies were ever called into question, Lill and Sabine did not hesitate to answer 'yes, of course', adding that they were certain this was a common experience for all women DJs. They recounted one incident in which a booking agent stated that he would provide them with a pre-mixed CD to 'perform', based on the assumption that they did not have the skills for live mixing. Such gendered prejudices about women's capacities for audio-technical expertise are not surprising, given the widespread tendency to describe 'technology' as a masculine domain (Armstrong, 2011; Born \& Devine, 2015; McClary, 1991).13

\section{'Fluffy' Timbres and the Voice}


In many of the dance music scenes that form around electronic music genres-for instance, drum 'n' bass, dubstep, house, techno or psytrance-musical sound itself is often discussed by DJs and clubbers with reference to gender (cf. Farrugia, 2012, pp. 8-10; see also Stirling, 2016). One theme raised insistently during my interviews with male DJs concerns the question of which types of sounds women or girls (usually portrayed as a homogeneous group) enjoy dancing to. Their own views assume causal relationships between 'getting women to dance' and the following three musical elements: prominent or catchy melodic riffs (particularly those in high registers); vocal lines (particularly those involving female voices); and soft or 'fluffy' timbres-as some participants referred to them. These widely shared beliefs determine a simple formula, understood as follows: if a DJ plays dance music with any of these features, women will dance; and if women are dancing, then menwho are assumed to be attracted to women-will also dance, thereby securing a full and successful dance floor for the DJ, and thus further bookings. One ex-DJ and producer, Warren, encapsulates this stance, showing how his choice to perform melodic tracks is informed by a crude gender stereotyping:

If you use some sort of melodic element, what we used to call fluffy-fluffy techno, or fluffy trance-then that's a way to get the girls dancing, very often, and once the girls start dancing, then everybody else starts dancing. That sounds like a cliché, but... it's just what happens. Every time, I've seen it. ${ }^{14}$

In a comparable example, Cam, an Edinburgh-based DJ and promoter, also reflects on the techniques that he uses to attract women to the dance floor:

There's always the old tricks like playing a record that's got a cheeky vocal in it or something. Get girls dancing, [and] generally you'll get boys dancing...that's a good rule to follow, and it's not something that I particularly like using because I don't really try to categorise my records as being, you know, 'oh that's one a bit more for the ladies'. I don't really like records like that; I like good electronic music, but there will be records where you know this one might get a few girls up dancing; and if you can get a wee troop of girls up, five girls up there that are on their own night out, then generally they will be followed by a pack of lads. And once you're on to, like, ten or fifteen people on the dance floor, it's much easier to build a dance floor. ${ }^{15}$

Cam explicitly contrasts tracks he deems to be attractive to women with his appreciation of 'good electronic music', arguing that there is a particular type of 'cheeky vocal' music that gets 'girls' dancing. This understanding that women initiate the process of dancing is not unique to contemporary club cultures, and significantly predates the 'rave' phenomenon, as demonstrated in Frith's (1978, p. 11) study of youth and music. Indeed, DJs' understandings of 'good electronic music' are tied up not only with issues of gender, but also with broader issues of taste, in the context of niche, genre-focused musical communities. Most notably, DJs in such 'alternative' scenes are concerned with how their practices and music differ from 'mainstream' 
club music and practices (Thornton, 1995). However, it is striking that in twenty-first century dance music settings, a 'formula' for making women dance has been identified by the male DJs I interviewed. Furthermore, even some women DJs refer to sounds as 'girly' in a derogatory manner. This reinforces the ubiquity of assumptions about the gendering of sounds in dance music environments.

The assumption that women prefer to dance to vocal lines is widespread among techno participants. As Frith (1996, p. 191) and Middleton (1990, pp. 261-264) both note, the voice in popular music serves as a reminder of the bodily origin of the music, although it is also detached from its embodied form through popular music's pervasive modes of technological mediation (Prior, 2009, pp. 91-94). Indeed, dancers can experience electronically produced sounds as disembodied due to the ambiguity of the sounds' sources. ${ }^{6}$ Yet, while dance music vocals are heavily 'produced', they are still recognisably derived from the human larynx; and for all the mediation, the voice, according to Frith, is in essence 'the sound of the body' (Frith, 1996, p. 192). What is more, the voice, according to both popular music scholars and music psychologists, invariably and unconsciously expresses aspects of physical and emotional feeling (Frith, 1996, p. 192; Hawkins, 2009, pp. 123-151; Middleton, 1990, p. 264; Trevarthen, Delafield-Butt, \& Schlöger, 2011). In some dance music genres, it is a key element in the most popular tracks, and is most noticeable when it is juxtaposed against an otherwise exclusively electronic soundscape. If the voice is simultaneously charged with these two traditionally feminine aesthetic qualities - the expression of emotion and an aural reminder of the body's materiality-then it is no surprise that the voice is also understood as the most feminine sound. The assumption that women like the voice may partly explain why it is consistently relied upon as a musical feature by producers and DJs in clubs. ${ }^{17}$ As demonstrated above in Cam's understanding of 'good electronic music', many DJs of all genders profess a distaste for vocal lines. Specifically, the voice undermines the 'underground' authenticity of the music that DJs choose to perform. Nonetheless, the chain of assumptions outlined earlier-the association of vocal lines with appeal to women, the assumption that women initiate dancing, and the notion that men will invariably follow - continue to motivate DJs to incorporate vocal lines in their tracks. Indeed, this series of interlocking assumptions appears to be pervasive even among DJs outside club settings. ${ }^{18}$

Gender-based stereotyping in dance music scenes extends beyond the aesthetics of music to assumptions about the aesthetics of dancing. ${ }^{19}$ Dance scholar Hall (2009) offers a close reading of this phenomenon based on the particular bodily movements associated with dancing to drum 'n' bass. Strikingly, Hall interprets the stylised movements of male dancers on drum 'n' bass dance floors as representative of an aggressive type of masculinity that she takes to be pervasive in the British drum 'n' bass scene (2009, pp. 203-205, 213-217). In parallel, other authors point to how the movements of women dancers in the 'male-coded spaces' (Gavanas \& Reitsamer, 2013, p. 57) of genres such as drum 'n' bass are scrutinised and excluded if they do not conform to the scene's expectations by those (mostly men) acting as cultural 
gatekeepers. Such gatekeeping, as I will show in the next section, permeates even in those settings considered by promoters, DJs and clubbers to be 'alternative' in their aesthetics and ethos.

\section{Circus and Resistance}

Circus is a popular techno and house club night in Edinburgh. The organisers of and participants in this club night view it as distinct from and 'alternative' to mainstream and commercial clubbing settings in terms of music, visual design, door policies, dancing styles and politics-including attitudes towards gender. Despite such selfdescribed progressive politics, in the interview excerpt below, Circus DJ and promoter Dom describes how women 'on a hen night' do not fit the normative (masculine) styles of dancing that he and others deem to be legitimate at techno club nights:

Somewhere like [venue name], when you get an influx of girls on a hen night, they don't dance the same way...even though they're listening to the same music. So they normally would maybe not [listen] to dance music, maybe more sort of R 'n' B, or chart orientated; so you get more of the girly dancing like that...You see, girls who are in with the electronic music crew dance the same way as the guys do. Whereas, with the sort of chart R'n' B, I think...people [are] a bit more reserved...20

In this quote, Dom argues explicitly that women who are out on a hen night either do not understand techno or do not dance properly to it. It is interesting to note that women on hen nights are the specific targets for Dom's criticism; men at stag nights do not receive a mention. For him, a division exists between the 'girly' dancing style of women on hen nights, honed by listening to $r$ 'n' $b$ or chart pop, and those women 'in with the electronic music crew', female techno participants who dance like the male techno aficionados. That is, the participation of women who are 'regulars' is validated in part by their choice to adopt masculine styles of dancing. Interviews with Dom and other Edinburgh techno DJs reveal an attitude to contemporary r ' $n$ ' $b$ that equates it with 'low' popular music genres whose associated dancing styles in club settings are explicitly sexual; indeed both the music and the dancing are signifiers, for Dom, of hen nights (and thus larger groups of women), low musical taste, dancing in a 'sexual' (feminine) manner, and-generally-not 'fitting in'.21

Nevertheless, explicitly oppositional ideologies and implicitly resistant practices do exist. In American as well as European and Australian techno and house scenes, for example, DJs, producers and clubbers have started to engage in complex gender political debates using social media. In parallel with these discussions, a critical shift in booking practices by a growing minority of promoters, club managers and booking agents is taking place with regard to gender policy. An increasing number of DJs, regardless of gender, have written policies into their contracts that allow them to reject event bookings that do not also include women DJs. 
Correspondingly, certain bookers have established policies of booking women for every gig they organise.

Some club nights incorporate a blurring of traditional gender, sexuality and other identity constructions into their branding, as well as actively promoting their dance floors as safe and respectful environments for all clubbers. At Circus, promoters and performers make explicit efforts to foster an environment free, for both DJs and audiences, from gender discrimination. This is in marked contrast to the marketing strategies of many other club nights I have observed and attended, which use consciously gender-discriminatory tactics to attract potential participants, such as encouraging women to dress in revealing clothing in return for free entry (Deal, 2011). Against this reality, the promoters from Circus avoid any consciously gender-discriminatory tactics to attract potential audiences. Circus participants, in turn, tend to display relatively progressive attitudes towards gender dynamics on the dance floors and behind the DJ booths. Even prevalent practices of aggressive heterosexual courtship on the dance floors are not merely avoided but frowned upon by Circus organisers, DJs and their networks of friends and fans. The collective sentiment of Circus club nights, coupled with a focus on flamboyant décor, themes and costuming (i.e. masquerade), creates a celebratory, carnivalesque environment in which gender, sexuality and other binding identity constructs are loosened.

Having made this point, I wish to emphasise that environments such as Circus and gender fluid or queer events are not entirely free from gender harassment. On one particular fieldwork night, I was myself physically harassed by a male clubber; in response, however, I gained the assistance of one of the promoters and DJs of the event. As Garcia (2011, pp. 97-113), notes, perceptions and expectations of sexual and nonsexual intimacy on dance floors can differ from one participant to the next. Clashes can erupt between those who seek fleeting experiences of sexual or druginduced freedom and intimacy, on the one hand, and those dancers approached by them who do not seek such experiences, on the other. Moreover, as I have observed at queer clubbing events, it is common for heterosexual men to attend such events with the intent to target heterosexual women who seek spaces for dancing in which they will not be harassed. Harassment still occurs, then, even in relatively openminded environments such as the Circus nights.

\section{Conclusion}

In this article, I have provided a reading of the gendered dynamics of DJ performances and dance music spaces, as well as the potential gender politics that they can prompt. As I mentioned at the outset, my interpretation diverges from the post-feminist and more broadly utopian-political interpretations provided by some writers. I noted the contributions of this scholarly literature to the idea that dance music environments lend themselves to the opening-up of gender relations; and I criticised the tendency in this literature to project the politics of certain dance floors in exceptional times and places onto the contemporary scenes they are researching. 
Analyses of US clubs, in particular queer New York clubs in the 1970s, for example, influenced the social configurations and politics of other contemporary clubbing spaces, including their openness to nonbinary gender relations. Similarly, rave dance floors in 1980 s Britain have been discussed in terms of their potential to dismantle social boundaries related to both gender and class. These scenes have been celebrated in dance music scholarship in part because they stand out from other scenes as particularly potent in their politics of emancipation. Yet, these politics resulted from specific conditions that may or may not be relevant to other scenes. Thus, discussions of the more current scenes referred to in this article are described in strikingly similar terms to those of both 1970 New York disco and 1980s UK rave. All in all, the widespread scholarly attention to scenes with alternative practices and politics, and the generally celebratory analyses of these scenes, contribute to a conflation across the literature of their particular qualities with a totalising, idealised account of 'dance music culture'. But the hyperfeminine stylisation of DJs through the promotion of such events as 'She Can DJ', the assumptions that women DJs are less competent both technically and musically, and the understanding that certain sonic features will 'make girls dance' only complement and thus bolster the pervasive male-gendering of both mainstream and so-called 'alternative' DJ cultures. This does very little to create events and spaces that are genuinely progressive in their gender attitudes and practices.

Throughout this article I have also maintained that although the unique, individual scenes and spaces of interest to many dance music scholars might foster a type of alternative politics of participation, they cannot lead us to assume that dance music culture at large has been able to break free from the pervasive gender dynamics immanent in everyday life. I have demonstrated this by underscoring a reality confronted by the women DJs that I interviewed, in line with the research of Farrugia (2012), and Gavanas and Reitsamer (2013): gender remains central to their performing identities.

I want to conclude, however, by reiterating the energetic emergence of genderconsciousness and debates about these issues in dance music and the music industry at large, along with the effects of this discourse on women participants. As I showed through the example of the Edinburgh techno and house night, Circus, scattered incarnations of the now-familiar idealised dance music scenes are evident. The success of these instances is surely influenced by a range of temporal and geographical contingencies, prominent among them the state of gender and sexuality politics, and culture and legislation in the society at issue during the period in which a dance music scene develops. Moreover, an increasing number of DJs of all genders (though largely women) are engaging in extensive social media discussions in which practical ideas for change are proposed and debated. Some of the issues raised in those discussions include the encouragement of gender-conscious hiring policies by booking agents, promoters and venue managers, as well as contractual agreements that insist upon equal opportunity. Such political acts constitute only some of the recent discursive shifts and calls to action by dance music participants. Together, these changes suggest that the prevailing problematic attitudes towards women DJs 
and women on dance floors may yet give way to tangible and even sustained improvements.

\section{Disclosure Statement}

No potential conflict of interest was reported by the author.

\section{Notes}

[1] I acknowledge that issues of gender, sexuality and race are inextricably interrelated. Nevertheless, despite links between these social categories, and regardless of their national, geographical, cultural or linguistic manifestations, I want to emphasise the common gender discriminations that proliferate across these realms.

[2] McRobbie (2009) has since revised her earlier theorisation of feminist resistance through popular cultural expression. She highlights, for example, the myriad problems with contemporary, consumer-focused representations of women in media such as magazines. However, her updated critique does not include a specific redress to the 'changing modes of femininity' on dance floors she previously described (1994). I make this point because many contemporary authors who discuss dance music culture implicitly replicate the utopian undertones of McRobbie's original (1994) analysis. Without focusing on gender in particular, such works address the potential for particular dance music environments to foster countercultures of freedom, agency and alternative politics (Lawrence, 2003; O’Grady, 2015; Petiau, 2015; Pini, 2001; Rietveld, 2011; Schmidt, 2015; St. John, 2013; Van Veen, 2010; Vitos, 2014; Watson, 2004).

[3] Despite how these scholars differentiate themselves from traditional subcultural theory and analysis, it is possible to identify in them an overarching tendency to interpret dance floors as potential spaces of emancipation (e.g. Malbon, 1999, pp. 1315; St. John, 2001, p. xv).

[4] Further discussion of women DJs can be found in journalism, where the issue of gender in dance music is gaining momentum. For example, Romano in the New York Times (2013) makes the point that almost all celebrity popular dance music DJs are men.

[5] I use pseudonyms for the interviewees, club nights and venues referred to throughout in this article.

[6] See http://www.femaledjs.com; www.female-djs.com. All URLs mentioned in this article were last accessed in December 2015.

[7] This phenomenon of the gender segmentation of the DJ market reflects a range of other consumer and service markets, and is considered 'fundamental' in marketing theory (McDonald, 2008; Oh, Parks, \& Demicco, 2002).

[8] Many DJs also perform 'anti-femininity', countering the trend for hyperfemininity in other DJ performances. For some performers, this is a consciously feminist act, 
while for others, it is a signifier of their lack of interest in 'girly' visual aesthetics, and by extension, musical aesthetics.

[9] As this incident illustrates, women can also be complicit in upholding the prejudicial attitudes and practices of harassment that women DJs encounter.

[10] Interview, Sydney, 2015.

[11] Interview, Reykjavík, 2015.

[12] Pre-interview email, Taipei, 2015.

[13] It is worth noting that a broad range of technologies are traditionally relegated only to women, such as those used in the private sphere. Farrugia (2012, pp. 19-22), for example, highlights how the marketing and manufacturing of audio technologies such as radios, aimed at women in the home, have been distinguished from those aimed at men, through their simplicity and user-friendliness. Thus, the problem of technology and gender-related prejudice pertains not so much to 'technologies' per se as standalone objects, but to the gendering of specific forms of technical know-how and skill, as these are incorporated into people's uses of these objects (see also Keightley, 1996).

[14] Interview, Edinburgh, 2010.

[15] Interview, Edinburgh, 2011.

[16] For a discussion of the tension between abstraction and the real-world associations of sounds in electronic dance music, see Gadir (2014, pp. 69-90). [17] See Frith (1996, pp. 193-196) on the relationship between the embodied voice and sex and sexuality.

[18] As a former wedding DJ myself, I was explicitly instructed by employers to play music with vocal lines to ensure that female guests would dance and men would follow.

[19] The language used to express this is often opaque; given their expertise, DJs and producers do not necessarily possess as well developed a vocabulary to describe dance movements as they do to describe and discuss music.

[20] Interview, Edinburgh, 2011.

[21] Frith and McRobbie's (1990) discussion of the prejudices in the rock world directed against women with regard to their 'pop' (low) musical tastes are evidently still applicable to attitudes in a number of popular electronic music scenes today.

\section{References}

Armstrong, V. (2011). Technology and the gendering of music education. Farnham: Ashgate.

Born, G., \& Devine, K. (2015). Music technology, gender, and class:

Digitization, educational and social change in Britain. Twentieth-Century Music, 12(2), 135-172.

Brewster, B., \& Broughton, F. (1999). Last night a DJ saved my life: The history of the disc jockey. New York, NY: Grove Press.

Butler, J. (1988). Performative acts and gender constitution: An essay in phenomenology and feminist theory. Theatre Journal, 4O(4), 519-531. 
Cheng, M. N.-H. (1998). Women conductors: Has the train left the station? Harmony: Forum of the Symphony Orchestra Institute, 6, 81-90.

Deal, S. (2011, July 20). 'Sluttiest dressed bird' promo causes outrage. The Metro, 15 .

Doubleday, V. (2008). Sounds of power: An overview of musical instruments and gender. Ethnomusicology Forum, 17(1), 3-39.

Farrugia, R. (2012). Beyond the dance floor: Female DJs, technology, and electronic dance music. Bristol: Intellect Books.

Fikentscher, K. (2000). You better work! A study of underground dance music in New York City. Hanover, NH: Wesleyan University Press.

Frith, S. (1978). Youth and music. In S. Frith (Ed.), (2007) Taking popular music seriously (pp. 1-30). Aldershot: Ashgate.

Frith, S. (1996). Performing rites: On the value of popular music. Cambridge, MA: Harvard University Press.

Frith, S., \& McRobbie, A. (1990). Rock and sexuality. In S. Frith, \& A. Goodwin (Eds.), On record: Rock, pop, and the written word (pp. 371-389). New York, NY: Pantheon Books.

Gadir, T. (2014). Musical meaning and social significance: Techno triggers for dancing (Unpublished doctoral dissertation). University of Edinburgh, UK.

Garcia, L. (2011). "Can you feel it, too?": Intimacy and affect at electronic dance music events in Paris, Chicago, and Berlin (Unpublished doctoral dissertation). University of Chicago, Chicago, IL.

Gavanas, A., \& Reitsamer, R. (2013). DJ Technologies, social networks and gendered trajectories in European DJ cultures. In B. A. Attias, A. Gavanas, \& H. C. Rietveld (Eds.), DJ culture in the mix: Power, technology, and social change in electronic dance music (pp. 51-78). New York, NY: Bloomsbury.

Hall, J. (2009). Heterocorporealities: Popular dance and cultural hybridity in UK drum 'n' bass culture (Unpublished doctoral dissertation). University of Surrey, Guildford.

Hawkins, S. (2009). Singing the body fantastic: Corporeality and the voice. In The British pop dandy (pp. 121-151). Farnham: Ashgate.

Hesmondhalgh, D. (2008). Towards a critical understanding of music, emotion and self-identity. Consumption, Markets and Culture, 11(4), 329-343.

Keightley, K. (1996). “Turn it down!” She shrieked: Gender, domestic space, and high fidelity, 1948-59. Popular Music, 15(2), 149-177.

Lawrence, T. (2003). Love saves the day: A history of American dance music culture, 1970-1979. Durham, NC: Duke University Press. Routledge.

Malbon, B. (1999). Clubbing: Dancing, ecstasy and vitality. London:

McClary, S. (1991). This is not a story my people tell. In Feminine endings: Music, gender and sexuality (pp. 142-147). Minneapolis: University of Minnesota Press.

McDonald, M. (2008). Market segmentation - A fundamental concept of marketing. In P. Sleight (Ed.), Targeting segmentation in marketing: From the fundamentals to the latest developments. The Marketing and Management Collection. London: Henry Stewart Talks. Retrieved April 05, 2016, from http://hstalks.com/?t=MMo551796

McRobbie, A. (1994). Postmodernism and popular culture. London: Routledge.

McRobbie, A. (2009). The aftermath of feminism. Los Angeles, CA: Sage. 
Middleton, R. (1990). Studying popular music. Milton Keynes: Open University Press.

O'Grady, A. (2015). Dancing outdoors: DiY ethics and democratised practices of well-being on the UK alternative festival circuit. Dancecult: Journal of Electronic Dance Music Culture, 7(1), 76-96.

Oh, H. Parks, S. C., \& Demicco, F. J. (2002). Age- and gender-based market segmentation. International Journal of Hospitality and Tourism Administration, 3(1), $1-20$.

Petiau, A. (2015). Free parties and teknivals: Gift-exchange and participation on the margins of the market and the State (L. Garcia, Trans.). Dancecult: Journal of Electronic Dance Music Culture, 7(1), 116-128.

Pini, M. (2001). Club cultures and female subjectivity: The move from home to house. New York, NY: Palgrave.

Prior, N. (2009). Software sequencers and cyborg singers: Popular music in the digital hypermodern. New Formations, 66, 81-99.

Reynolds, S. (2008). Energy flash: Into the world of techno and rave culture. London: Picador.

Rietveld, H. C. (2011). Disco's revenge: House music's nomadic memory. Dancecult: Journal of Electronic Dance Music Culture, 2(1), 4-23.

Robertson, C. E. (1987). Power and gender in the musical experiences of women. In E. Koskoff (Ed.), Women and music in cross-cultural perspective (pp. 225-244). Champaign: University of Illinois Press.

Romano, T. (2013, November 1). Women edging their way into the D.J. Booth. New York Times. Retrieved April 05, 2016, from http://www.nytimes.com/2013/11/03/arts/music/womenedgingtheir-way-into-the-dj-booth.html

Saldanha, A. (2001, March). Music-bodies-politics: Geographies of psychedelic rave culture in Goa. Paper presented at the 'Sonic geographies' session, 93rd Annual Meeting of the American Association of Geographers, New York, NY.

Schmidt, B. (2015). Boutiquing at the raindance campout: Relational aesthetics as festival technology. Dancecult: Journal of Electronic Dance Music Culture, $7(1)$, 35-54.

Shapiro, P. (Ed.). (2000). Modulations: A history of electronic music. New York, NY: Caipirinha Productions.

Sicko, D. (1999). Techno Rebels: The renegades of electronic funk. New York, NY: Billboard Books.

St. John, G. (Ed.). (2001). Free NRG: Notes from the edge of the dancefloor. Altona: Common Ground.

St. John, G. (2013). Aliens are us: Cosmic liminality, remixticism, and alienation in psytrance. The Journal of Religion and Popular Culture, 25(2), 186204.

Stirling, C. (2016). 'Beyond the dance floor?' Gendered publics and creative practices in electronic dance music. Contemporary Music Review, 35(1), 130-149. Thornton, S. (1995). Club cultures: Music, media and subcultural capital. Cambridge: Polity Press.

Trevarthen, C., Delafield-Butt, J., \& Schögler, B. (2011). Psychobiology of musical gesture: Innate rhythm, harmony and melody in movements of narration. In A. Gritten, \& E. King (Eds.), New perspectives on music and gesture (pp. 11-43). Farnham: Ashgate. 
Van Veen, T. (2010). Technics, precarity and exodus in rave culture. Dancecult: Journal of Electronic Dance Music Culture, 1(2), 29-49.

Vitos, B. (2014). "An avatar...in a physical space": Researching the mediated immediacy of electronic dance floors. Dancecult: Journal of Electronic Dance Music Culture, 6(2), 1-21.

Waters, S. (2016). Engendering hope: A person-centred reflection on technology and gender. Contemporary Music Review, 35(1), 61-70.

Watson, S. (2004). Cultures of democracy: Spaces of democratic possibility. In C. Barnett, \& M. Low (Eds.), Spaces of democracy: Geographical perspectives on citizenship, participation and representation (pp. 207-222). London: Sage. 